\title{
GENERAL EQUILIBRIUM FEEDBACK REGARDING THE EMPLOYMENT EFFECTS OF LABOR TAXES
}

\author{
MinCHul Yum \\ University of Mannheim
}

\begin{abstract}
A higher labor tax rate increases the equilibrium real interest rate and reduces the equilibrium wage in a heterogeneous-agent model with endogenous savings and indivisible labor supply decisions. I show that these general equilibrium (GE) adjustments, in particular of the real interest rate, reinforce the negative employment impact of higher labor taxes. However, the representative-agent version of the model, which generates similar aggregate employment responses to labor tax changes, implies that GE feedback is neutral. The cross-country panel data reveal that the negative association between labor tax rates and the extensive margin labor supply is significantly and robustly weaker in small open economies where the interest rate is less tightly linked to domestic circumstances. This empirical evidence supports the transmission mechanism of labor tax changes for employment in the heterogeneous-agent model.
\end{abstract}

Keywords: Labor Income Tax, Labor Supply Elasticity, General Equilibrium, Cross-Country Panel

\section{INTRODUCTION}

The goal of this paper is to explore general equilibrium (GE) feedback regarding the employment effects of labor tax changes. The degree to which labor taxes affect employment and aggregate hours worked is central to various questions in economics. ${ }^{1}$ Although recent studies of aggregate labor supply in the macroeconomics literature increasingly adopt richer and more realistic models, little attention has been given to the role of GE feedback. ${ }^{2}$ GE considerations are often assumed away by exogenously setting a fixed interest rate (so-called a small open economy assumption) or fixed wages in partial equilibrium settings. This paper

I thank Lee Ohanian (co-editor) and two anonymous referees for helpful comments that improved the paper substantially. For constructive suggestions and discussions, I am also grateful to Yongsung Chang, Georg Duernecker, Tom Krebs, Tim Lee, Jim MacGee, Dmitry Matveev, Yongseok Shin, Saverio Simonelli, Takeki Sunakawa, and Jinhee Woo as well as seminar participants at the University of Mannheim, the North American Summer Meeting of the Econometric Society in Philadelphia, 2016 KAEA-KEA International Conference, Asian Meeting of Econometric Society in Kyoto, and 2016 KIPF-KAEA Joint Conference and Kobe University. I gratefully acknowledge funding by the German Research Foundation (DFG) through CRC TR 224. This paper uses data from the Eurosystem Household Finance and Consumption Survey. An earlier version of this paper was titled "On the Employment Effects of Taxes: A General Equilibrium Analysis.” Address correspondence to: Minchul Yum, L 7, 3-5, P09, Department of Economics, University of Mannheim, 68161 Mannheim, Germany. e-mail: minchul.yum@uni-mannheim.de. Phone: +49 (0)621-181-1853. 
fills this void and intends to enhance the understanding of GE channels through which labor taxes affect employment.

I first conduct a quantitative theoretical analysis based on (i) a heterogeneousagent model with indivisible labor supply and incomplete asset markets, built upon Chang and Kim (2006) and Alonso-Ortiz and Rogerson (2010) and (ii) its representative-agent counterpart [Hansen (1985) and Rogerson (1988)]. The main finding is that the transmission mechanism through which labor tax changes affect employment in the two economies differs sharply, despite similar aggregate employment responses to labor tax changes. ${ }^{3}$ Specifically, GE feedback with respect to labor tax changes reinforces negative employment responses in the heterogeneous-agent model, whereas it plays no role in the representativeagent model. A novel contribution of this paper is the emphasis on the role of the equilibrium interest rate that is found to be quantitatively relevant in amplifying the negative employment impact of labor taxes. In particular, despite the fact that labor tax changes lead to seemingly small changes in the real interest rate, I find that these interest rate changes affect aggregate employment quite substantially, increasing the long-run labor supply elasticity from 0.18 to 0.34 in the heterogeneous-agent model. ${ }^{4}$

I show that this GE feedback can be traced to the heterogeneous behavior of households. Specifically, in the heterogeneous-agent model, the labor supply behavior of households with high productivity is nearly inelastic to labor tax changes, whereas their savings behavior is very much affected by labor tax changes. ${ }^{5}$ As a result, the aggregate efficiency unit of labor falls relatively less than other macroeconomic aggregates, including aggregate capital stock, with respect to higher labor taxes. This leads to lower equilibrium wages and higher equilibrium interest rates, both of which tend to reinforce the negative impact of labor taxes on employment. Note that this mechanism emphasizes GE feedback resulting from interactions between the labor market and the capital (or asset) market, in contrast to conventional GE considerations, which focus on market-clearing wages within labor markets.

I also conduct an empirical analysis to test the novel implication of the heterogeneous-agent model relative to the representative-agent model: interest rate adjustments matter for the employment effects of labor taxes. As the interest rate in small open economies (SOEs) is less tightly linked to domestic circumstances, a testable implication of the theory is whether the negative employment impact of higher labor taxes is weaker or not among SOEs, compared to nonSOEs. Using a fairly large cross-country panel data set, I first document that the negative relationship between the labor tax rate and the extensive margin labor supply is considerably flatter among SOEs. Moreover, labor supply elasticities, estimated from panel regressions in the spirit of Prescott (2004) and Chetty et al. (2012), show that the elasticity among SOEs is significantly lower than that among non-SOEs, which is in line with the transmission mechanism of labor tax changes on aggregate employment in the heterogeneous-agent model.

This paper builds on the literature that compares the aggregate labor supply implications of heterogeneous-agent models compared to representative-agent 
models. ${ }^{6}$ As in Ljungqvist and Sargent (2008) and Alonso-Ortiz and Rogerson (2010), my paper also confirms that household heterogeneity per se may not be crucial in terms of aggregate employment responsiveness to labor tax changes. However, my paper is distinguished from the existing studies in carrying out decomposition of aggregate employment changes and in highlighting the role of GE feedback explicitly. Further, my paper also conducts an empirical analysis using cross-country panel data, providing empirical support for the heterogeneous-agent model over the representative-agent model unlike the aforementioned papers.

In the next section, I describe the environment of the model economies. Section 3 presents calibration, and Section 4 presents the main quantitative analysis. Section 5 explores empirical evidence related to the findings in Section 4. Section 6 concludes the paper.

\section{MODEL ECONOMIES}

This section describes two model economies used for the quantitative theoretical analysis in the following sections. The two model economies share the same economic environment such as the production sector, government sector, and the indivisibility of labor supply, but differ in terms of household heterogeneity.

\subsection{Heterogeneous-Agent Model}

I first present the heterogeneous-agent model, which is a standard GE model with incomplete markets [Imrohoroğlu (1989), Huggett (1993), and Aiyagari (1994)].

Households. There is a continuum of infinitely lived households who differ in their asset holdings $a$ and productivity $x$ in each period. A household decides how much to consume $c$ and save for the next period $a^{\prime}$. The productivity $x \in\left\{x_{1}, x_{2}, \ldots, x_{N_{x}}\right\}$ follows a Markov chain with transition probabilities $\left\{\pi_{i j}\right\}_{i, j=1}^{N_{x}}$, where $\pi_{i j} \equiv \operatorname{Pr}\left(x_{j}^{\prime} \mid x_{i}\right)$. This idiosyncratic uncertainty cannot be fully insured because $a$ is the only asset available to households. Labor supply is endogenous at the extensive margin [Rogerson (1988) and Chang and Kim (2006)]. The competitive factor markets imply that households take as given the wage rate per efficiency unit of labor $w$ and the real interest rate $r$. Households also take as given the labor income tax $\tau_{l}$, capital income tax $\tau_{k}$, and transfers $T$.

The functional equation summarizing the decision problem of households is given by $V\left(a, x_{i}\right)=\max \left\{W\left(a, x_{i}\right), N\left(a, x_{i}\right)\right\}$, where the value of working, $W\left(a, x_{i}\right)$, and the value of non-working, $N\left(a, x_{i}\right)$, are defined as

$$
\begin{aligned}
& \qquad W\left(a, x_{i}\right)=\max _{a^{\prime} \geq \underline{a},}\left\{\log c-\Gamma \bar{h}+\beta \sum_{j=1}^{N_{x}} \pi_{i j} V\left(a^{\prime}, x_{j}^{\prime}\right)\right\} \\
& \text { s.t. } \quad c+a^{\prime} \leq\left(1-\tau_{l}\right) w x_{i} \bar{h}+\left(1+r\left(1-\tau_{k} I(a>0)\right)\right) a+T(\cdot),
\end{aligned}
$$




$$
\begin{aligned}
& \quad N\left(a, x_{i}\right)=\max _{a^{\prime} \geq \underline{a},}\left\{\log c+\beta \sum_{j=1}^{N_{x}} \pi_{i j} V\left(a^{\prime}, x_{j}^{\prime}\right)\right\} \\
& \text { s.t. } \quad c+a^{\prime} \leq\left(1+r\left(1-\tau_{k} I(a>0)\right)\right) a+T(\cdot) .
\end{aligned}
$$

Households face budget constraints: the sum of current consumption and asset demands for the next period should not be greater than the sum of net-of-tax labor income $\left(1-\tau_{l}\right) w x_{i} \bar{h}$ (if they choose to work), current asset holdings $a$, net-of-tax capital income $r\left(1-\tau_{k}\right) a$, and transfers according to the schedule $T(\cdot)$. $I(a>0)$ is an indicator function such that capital income tax is only imposed when $a$ is positive. Households can borrow up to the limit $a \leq 0$. If households choose to work, they earn labor income in return for disutility $\Gamma \bar{h}$ where $\Gamma$ is disutility per hour and $\bar{h}$ is the full-time hours of work. Households' expected future value $\sum_{j=1}^{N_{x}} \pi_{i j} V\left(a^{\prime}, x_{j}^{\prime}\right)$ is discounted by a discount factor $\beta \in(0,1)$.

Firm. There is a representative firm that produces aggregate output $Y$. Production technology is captured by a standard constant-returns-to-scale production function $F(K, L)$, where the factors of production include capital $K$ and aggregate efficiency units of labor $L$. The competitive firm takes prices, $r$ and $w$, as given and solves the following profit maximization problem:

$$
\max _{K, L}\{F(K, L)-(r+\delta) K-w L\}
$$

where $\delta$ is the depreciation rate. As is standard in the literature, a Cobb-Douglas function is used for production technology: $F(K, L)=K^{\alpha} L^{1-\alpha}$.

Government. There is a government which levies proportional income taxes on labor $\tau_{l}$ and capital $\tau_{k}$. Using the collected tax revenues, the government provides transfers $T(\cdot)$ and spends $G$ while balancing its budget each period.

Although the focus of this paper is not on government transfers, it is important to introduce transfers in order to match the wealth gradient of employment rates in this class of models [Yum (2018)]. Following Krusell and Rios-Rull (1999), I assume that transfers consist of two components: $T=T_{1}+T_{2}$, where $T_{1}$ is given to all households equally and $T_{2}$ is the income security component. Then, $T_{2}$ is allowed to be progressive following the functional form: $T_{2}(x)=\omega_{0} \exp \left(-\omega_{1} x\right)$. Note that there are two parameters shaping $T_{2}$. The first parameter $\omega_{0} \geq 0$ is a scale parameter. When $\omega_{0}$ becomes higher, the second component of transfers $T_{2}$ becomes relatively larger. The second parameter $\omega_{1} \geq 0$ captures the progressivity of the transfer system. A higher $\omega_{1}$ implies that $T_{2}$ decreases faster with productivity. As shown in Section 3, this parsimonious progressive transfer structure allows the model to successfully replicate the observed progressivity of government transfers across wealth quintiles. Government purchase $G$ is determined to balance the period government budget constraint. $^{7}$ 
Equilibrium. A recursive competitive equilibrium is a set of factor prices, $w, r$, aggregate allocations, $K, L$, household's decision rules $g(a, x), h(a, x)$, value functions $V(a, x), W(a, x), N(a, x)$, government policy variables $\tau_{l}, \tau_{k}, T(\cdot), G$, and the distribution of households over the individual state space $\mu(a, x)$ such that

1. Given factor prices $w, r$, the value functions $V(a, x), W(a, x), N(a, x)$ solve the household's decision problems, and $g(a, x), h(a, x)$ are the associated decision rules.

2. Given factor prices $w, r$, the firm optimally chooses $K^{d}$ and $L^{d}$ following

$$
\begin{gathered}
w=(1-\alpha)\left(\frac{K^{d}}{L^{d}}\right)^{\alpha}, \\
r=\alpha\left(\frac{K^{d}}{L^{d}}\right)^{\alpha-1}-\delta .
\end{gathered}
$$

3. Markets clear:

$$
\begin{gathered}
\sum_{i=1}^{N_{x}} \int g\left(a, x_{i}\right) \mu\left(d a, x_{i}\right)=K^{d}=K, \\
\sum_{i=1}^{N_{x}} \int x_{i} h\left(a, x_{i}\right) \mu\left(d a, x_{i}\right)=L^{d}=L .
\end{gathered}
$$

4. Government balances its budget:

$$
G+\sum_{i=1}^{N_{x}} \int_{0}^{\infty} T\left(x_{i}\right) \mu\left(d a, x_{i}\right)=\tau_{l} w L+\tau_{k} r \sum_{i=1}^{N_{x}} \int_{0}^{\infty} a \mu\left(d a, x_{i}\right) .
$$

5. The distribution of households is stationary: $\mu\left(a^{\prime}, x^{\prime}\right)$ implied by $g(a, x), h(a, x)$, $\left\{\pi_{i j}\right\}_{i, j=1}^{N_{x}}$ and $\mu(a, x)$ is again $\mu(a, x)$.

\subsection{Representative-Agent Model}

This subsection presents the representative-agent counterpart of the heterogeneous-agent model introduced in the previous subsection. Since the only difference between the two models is in the household sector, I describe the household sector of this representative-agent economy.

The economy is populated by a continuum of infinitely lived households whose productivity is homogeneous. I maintain the same assumption that labor supply is indivisible at the individual level; that is, each household can supply either 0 or $\bar{h}$ hours of work. Following the aggregation theory in Rogerson (1988), one can show that the stand-in household period utility function has a key feature that disutility of work is linear in employment. ${ }^{8}$

The stand-in household's dynamic problem in this representative-agent model is written as

$$
\begin{gathered}
V(K)=\max _{\substack{K^{\prime}>0, E \in[0,1]}}\left\{\log C-\Gamma E+V\left(K^{\prime}\right)\right\} \\
\text { subject to } C+K^{\prime} \leq\left(1-\tau_{l}\right) w E+\left(1+r\left(1-\tau_{k}\right)\right) K+T,
\end{gathered}
$$


where the household chooses the optimal consumption $C$ (or savings $K^{\prime}$ ) and the optimal fraction of the employed $E \in[0,1]$. The remaining elements such as taxes $\tau_{l}, \tau_{k}$ and transfers $T$ (in terms of size) are identical to those in the heterogeneous-agent model. The steady-state competitive equilibrium of this representative-agent model can be solved analytically (see Supplementary Appendix).

\section{CALIBRATION}

The model economies are calibrated to US data. A model period is a year. There are two sets of parameters. The first set is chosen externally and is common between the heterogeneous-agent model and the representative-agent model. The second set of parameters is determined internally to make the model behave similarly in terms of several key statistics obtained from the 2005 Panel Study of Income Dynamics (PSID) with the Supplemental Wealth File and the 2001 Survey of Income and Program Participation (SIPP). ${ }^{9}$

Parameters calibrated externally. Most of the parameters calibrated externally are commonly used in the quantitative macroeconomics literature, and their values are set following Alonso-Ortiz and Rogerson (2010). The first parameter $\alpha$ is set to 0.36 , consistent with the capital share in the aggregate US data. The annual capital depreciation rate $\delta$ is equal to 0.096 . The baseline tax rate on labor income $\tau_{l}$ is equal to 0.3 , as in other related studies [Krusell et al. (2008, 2010), and Alonso-Ortiz and Rogerson (2010)]. ${ }^{10}$ I set $\tau_{k}$ equal to 0.38 , which is in between the values in Domeij and Heathcote (2004) and Trabandt and Uhlig (2011). The parameter for the full-time hours of work, $\bar{h}$, is set to 0.407 .

The Markov chain, $\left\{x_{i}\right\}_{i=1}^{N_{x}}$ and $\left\{\pi_{i j}\right\}_{i, j=1}^{N_{x}}$, in the heterogeneous-agent model is assumed to approximate a continuous AR(1) process, $\log x^{\prime}=\rho \log x+\varepsilon^{\prime}$, where $\varepsilon$ is normally distributed with mean zero and the standard deviation of $\sigma_{x}$, following Rouwenhorst (1995). The two parameters $\rho_{x}$ and $\sigma_{x}$ are set to 0.94 and 0.205 , as in Alonso-Ortiz and Rogerson (2010).

Parameters calibrated internally. The remaining parameters are jointly calibrated to match the same number of target statistics. In the heterogeneous-agent model, these parameter values are determined as minimizers of the distance between the relevant statistics from US data and those from the model-generated data. In the representative-agent model, I use the equations that characterize the steady-state equilibrium to calibrate these parameters.

The first parameter in Table 1 is $\beta$, which is the discount factor. This parameter is calibrated to match the steady-state real interest rate of $4 \%$. Next, $\Gamma$ is the parameter capturing the disutility of work. The relevant target is the aggregate employment rate. According to the 2005 PSID, this ratio is $77.6 \%$, which is used as another target statistic. Finally, $\underline{a}$ is the borrowing limit, which is relevant for the heterogeneous-agent model. The target statistic for this parameter is set as 
TABLE 1. Parameters chosen internally using simulation

\begin{tabular}{lccl}
\hline & \multicolumn{2}{c}{ Model } & \\
\cline { 2 - 3 } Parameter & HA & RA & \multicolumn{1}{c}{ Target statistics } \\
\hline$\beta$ & 0.9649 & 0.9758 & Steady-state interest rate \\
$\Gamma$ & 1.575 & 0.9317 & Employment rate \\
$a$ & -0.183 & - & Share of wealth by 1st quintile \\
$T_{1}$ & 0.0504 & 0.142 & Flat transfers-output ratio \\
$\omega_{0}$ & 0.355 & - & Progressive transfers-output ratio \\
$\omega_{1}$ & 3.26 & - & Progressivity of transfer schedule \\
\hline
\end{tabular}

the share of wealth among the first wealth quintile $(-1.1 \%)$ in the same PSID data set.

The next three parameters govern the government transfer system. Recall that the parameter $T_{1}$ determines the size of flat government transfers, whereas $\omega_{0}$ determines the size of progressive transfers. Since these two components can be distinguished in the heterogeneous-agent model, their relevant target statistics are set to be $6.8 \%$ and $3.8 \%$ of output, respectively [Krusell and Rios-Rull (1999)]. On the other hand, the representative-agent model, which lacks heterogeneity, cannot incorporate progressivity. Therefore, $\omega_{0}$ is irrelevant and $T_{1}$ is directly calibrated to match an aggregate transfers-output ratio of $10.6 \%$. In the USA, the presence of various means-tested programs leads to the fact that the poor households receive a substantially larger amount of transfers related to income security. The parameter $\omega_{1}$, which shapes the progressivity of $T_{2}$, is calibrated to match the relative size of income security transfers going to the households in the bottom wealth quintile compared to its unconditional mean (2.36). ${ }^{11}$

Although not reported, all model specifications with the reported calibrated values can match the target statistics precisely. In addition, by construction, all of the model specifications have the same capital-output ratio (2.65).

Distributional properties of the heterogeneous-agent model. In the heterogeneous-agent model, the distribution of wealth is an endogenous object. Thus, I check how the heterogeneous-agent model performs in terms of nontargeted moments across the distribution of wealth. The first row in Table 2 shows the wealth share by each wealth quintile in the USA. The first two rows show that the heterogeneous-agent model does a good job of matching the distribution of wealth in the data. In particular, the model implies that the top wealth quintile holds close to $76 \%$ of the total wealth, which is close to $79 \%$ in the data.

Table 2 also reports employment rates by wealth quintile. In US data, employment rates by wealth quintile are relatively flat or slightly inverse U-shaped. Specifically, the employment is relatively low among the bottom wealth quintile $(69 \%)$ and is quite flat around $82 \%$ in the second to fourth wealth quintiles. 
TABLE 2. Disaggregated statistics by wealth quintile: data and model

\begin{tabular}{lccccc}
\hline & \multicolumn{5}{c}{ Wealth quintile } \\
\cline { 2 - 6 } & First & Second & Third & Fourth & Fifth \\
\hline Wealth share (\%) & & & & & \\
Data (PSID) & -1.1 & 1.0 & 5.3 & 16.5 & 78.6 \\
HA model & -1.1 & 0.2 & 5.1 & 19.8 & 75.9 \\
Employment rate (\%) & & & & & \\
Data (PSID) & 68.8 & 81.1 & 83.3 & 82.3 & 72.8 \\
HA model & 71.7 & 90.7 & 85.0 & 76.1 & 64.5 \\
$T_{2}$ relative to E(T $\left.T_{2}\right)$ & & & & & \\
Data (SIPP) & 2.36 & 1.36 & 0.72 & 0.34 & 0.21 \\
HA model & 2.36 & 1.05 & 0.69 & 0.53 & 0.37 \\
\hline
\end{tabular}

Note: The distributional statistics in the USA are obtained from the 2005 PSID with Supplemental Wealth File and 2001 SIPP.

Then, the employment rate among the top wealth quintile is lower at $73 \%$. The heterogeneous-agent model which incorporates progressive transfers and capital taxation does an excellent job of matching the employment rates by wealth quintile [Yum (2018)].

Finally, the last two rows in Table 2 show the conditional mean of $T_{2}$ in each wealth quintile relative to the unconditional mean of $T_{2}$. Note that although the calibration only targets the first wealth quintile (2.36), the functional form assumed in Section 2.1 does a good job of accounting for the observed degree of progressivity in income-security programs in the USA.

\section{QUANTITATIVE ANALYSIS USING MODEL ECONOMIES}

This section presents the main quantitative-theoretic analysis using the calibrated model economies.

\subsection{Employment Response to Labor Tax Changes in Model Economies}

I begin by presenting equilibrium employment responses with respect to changes in the labor tax rate $\tau_{l}$ in the model economies [e.g., Krusell et al. (2008, 2010), Rogerson and Wallenius (2009), and Alonso-Ortiz and Rogerson (2010)]. In doing so, I consider two cases given that a change in $\tau_{l}$ affects the government budget constraint (5). The first case assumes that $G$ is adjusted to balance the government budget while holding $T$ fixed. I consider this case as the baseline in the next subsection because this assumption simplifies the decomposition exercise by muting additional feedback effects from a change in $T$. However, in the current subsection, I also consider the second case in which $T$ is adjusted (in the heterogeneous-agent model, $T_{1}$ and $T_{2}$ are adjusted in the same proportion) while holding $G$ fixed. This assumption allows for feedback through $T$ because a 
TABLE 3. Labor taxes and employment rates in the USA and in Europe

\begin{tabular}{lcccccc}
\hline & \multicolumn{5}{c}{ Employment rates } \\
\cline { 2 - 7 } & & \multicolumn{5}{c}{ By wealth quintile } \\
\cline { 3 - 7 } Unit: \% & In aggregate & First & Second & Third & Fourth & Fifth \\
\hline HA model: $\tau_{l}=0.45$ & & & & & & \\
$G$ adjusts (holding $T$ fixed) & 70.7 & 62.6 & 83.2 & 78.2 & 71.9 & 57.8 \\
$T$ adjusts (holding $G$ fixed) & 61.9 & 49.1 & 68.4 & 69.6 & 66.3 & 56.1 \\
Data $(H F C S)$ & & & & & & \\
France & 60.7 & 46.2 & 72.3 & 70.7 & 59.7 & 54.6 \\
Germany & 62.3 & 44.3 & 59.6 & 72.4 & 72.1 & 63.3 \\
Italy & 53.3 & 49.4 & 61.2 & 50.9 & 52.6 & 52.6 \\
\hline
\end{tabular}

Note: Employment rates by wealth quintile in European countries are computed by the author using samples from the Eurosystem Household Finance and Consumption Survey.

higher tax would increase $T$, which in turn has negative income effects on labor supply.

Table 3 first shows the equilibrium employment responses with respect to $\tau_{l}=0.45$, implied by the heterogeneous-agent model. It shows employment changes both in aggregate and by wealth quintile. Given that the labor tax rate of $45 \%$ is close to the tax rate in continental European countries such as France, Germany, and Italy, it is interesting to investigate how the model accounts for not only aggregate employment but also employment rates across wealth distribution. First, note that, in line with Prescott (2004), Ohanian et al. (2008), and Rogerson (2008), I find that labor taxes in my heterogeneous-agent model can largely account for the difference in the aggregate employment level between the USA and European countries, especially when $T$ is adjusted accordingly. More importantly, my model implies that the employment rate by wealth quintile features a clear inverse U-shape when $\tau_{l}$ is set to be $45 \%$. The last three rows in Table 3 show that this shape is very close to its counterpart in France, Germany, and Italy, constructed using samples from the Eurosystem's Household Finance and Consumption Survey. This highlights that the heterogeneous-agent model is able to account for not only the aggregate employment pattern but also distributional aspects in employment.

Table 4 presents the employment rate as a function of net-of-tax rates for a range of labor tax rates, implied by both the heterogeneous-agent model and the representative-agent model. ${ }^{12}$ The first thing to note is that both models predict sizeable effects of labor taxes on aggregate employment, especially when $T$ adjusts. More importantly, given the same fiscal responses, two models generate similar aggregate employment responses to labor tax changes, confirming the near-equivalence result in terms of aggregate employment responses between the heterogeneous-agent model and the representative-agent model in the literature. ${ }^{13}$

In addition to Table 4 , the following regression provides a more concrete number (i.e., the labor supply elasticity) that measures the degree of employment 
TABLE 4. Labor taxes and aggregate employment in model economies

\begin{tabular}{lccccccc}
\hline \multicolumn{1}{c}{$\tau_{l}=$} & 0.15 & 0.20 & 0.25 & 0.30 & 0.35 & 0.40 & 0.45 \\
\hline $\begin{array}{l}\text { G adjusts (holding T fixed) } \\
\text { HA model }\end{array} \quad 105.7$ & 104.0 & 102.1 & 100.0 & 97.0 & 94.1 & 91.2 \\
RA model & 106.0 & 104.2 & 102.2 & 100.0 & 97.5 & 94.5 & 91.2 \\
$\begin{array}{l}\text { T adjusts (holding G fixed) } \\
\text { HA model }\end{array}$ & 116.6 & 112.7 & 106.6 & 100.0 & 93.1 & 86.1 & 79.8 \\
RA model & 117.8 & 111.9 & 105.9 & 100.0 & 94.1 & 88.1 & 82.2 \\
\hline
\end{tabular}

Note: Reported numbers are relative to the benchmark case with the labor income tax rate of $30 \%$ for each specification (normalized to 100).

responsiveness to net-of-tax changes in percentage term [e.g., Chetty et al. (2012)]:

$$
\log E=\beta_{0}+\beta_{1} \log \left(1-\tau_{l}\right)+\varepsilon,
$$

where $E$ refers to employment. The estimate of $\beta_{1}$ is 0.347 in the heterogeneousagent model and it is 0.353 in the representative-agent model when $G$ adjusts holding $T$ fixed. In the case when $T$ adjusts holding $G$ fixed, it is 0.898 in the heterogeneous-agent model and 0.827 in the representative-agent model. These similar slope estimates clearly demonstrate that household heterogeneity may not be crucial at least when it comes to aggregate employment responsiveness to labor tax changes.

\subsection{Decomposing Equilibrium Employment Changes}

I now move on to the main question of this paper: transmission channels through which labor tax changes affect aggregate employment. Note that even if the aggregate employment responses are similar, the underlying transmission channels could differ substantially. An equilibrium aggregate employment response with respect to labor tax changes can be decomposed as follows: ${ }^{14}$

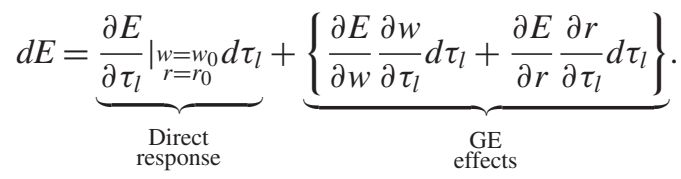

Specifically, an equilibrium change in employment $(d E)$ with respect to a change in the labor tax $\left(d \tau_{l}\right)$ can be decomposed into several components. The first term on the right-hand side captures the employment change driven directly by labor tax changes while holding fixed equilibrium changes such as the wage and real interest rate. Because changes in labor taxes could influence equilibrium factor prices, the equilibrium employment change can be affected additionally by the second part (GE effects) - the sum of employment changes caused by changes in wage $w$ and real interest rate $r$. It should be noted that each GE effect can be either 


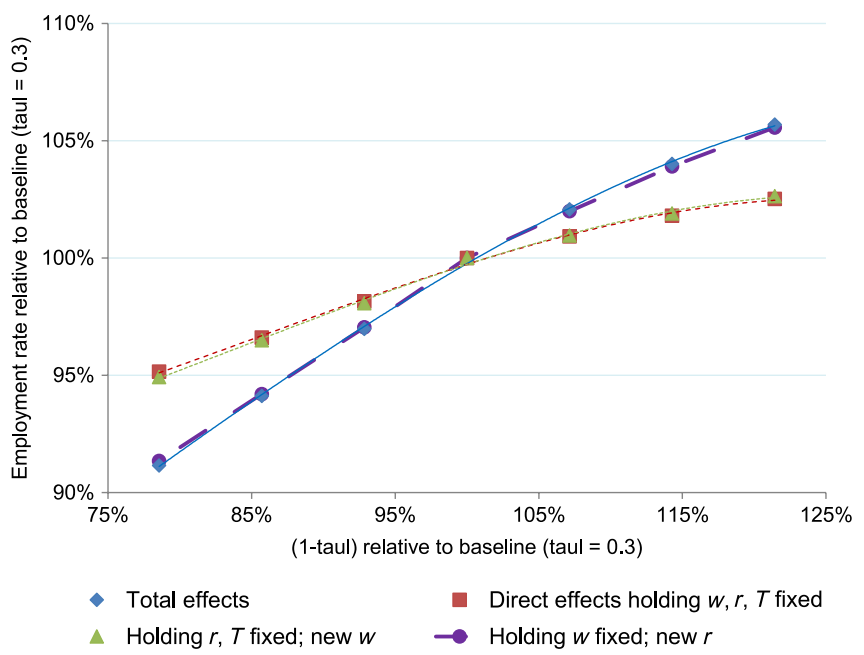

Notes: The figure is based on the assumption that $G$ adjusts with respect to a change in the labor tax. The solid line is the equilibrium employment responses to tax changes in GE. The dashed line is the direct response while holding factor prices fixed at the baseline level with a tax rate of 0.3 . The dotted line refers to the employment responses to tax changes when, on top of the direct effects, equilibrium wage adjustments are accounted for. The long-dashed line captures the effects when equilibrium interest rate changes are accounted for.

FIGURE 1. Decomposition of employment changes in the heterogeneous-agent model.

positive or negative depending on the sign of each sub-term (i.e., $\frac{\partial E}{\partial w}, \frac{\partial w}{\partial \tau_{l}}, \frac{\partial E}{\partial r}$ and $\frac{\partial r}{\partial \tau_{l}}$ ). In other words, GE feedback may reinforce or dampen the negative effects of labor taxes on employment.

As for the decomposition in the heterogeneous-agent model, a graphical presentation of the results is useful. In Figure 1, I first plot the changes in employment solely based on direct effects (dashed line) and the equilibrium effect (solid line). ${ }^{15}$ It is clear that the heterogeneous-agent model that produces sizable employment responses to labor taxes in GE predicts substantially weaker direct employment responses. A natural question that follows is the source of this sizeable gap. Figure 1 also plots the employment responses incorporating not only the direct effect but also effects induced by an additional channel one by one: (i) the wage channel (dotted line) and (ii) the interest rate channel (long-dashed line). There are two noteworthy findings. First, the contribution of adjustments in equilibrium wage $\left(\frac{\partial E}{\partial w} \frac{\partial w}{\partial \tau_{l}} \partial \tau_{l}\right)$ is positive but quantitatively small. Second, adding the real interest rate channel $\left(\frac{\partial E}{\partial r} \frac{\partial r}{\partial \tau_{l}} \partial \tau_{l}\right)$ brings the employment effects noticeably closer to the equilibrium effect, showing that adjustments in the interest rate reinforce the direct employment response to labor taxes considerably.

In the case of the representative-agent model, this decomposition is trivial due to the following results. The proofs are in Supplementary Appendix. 
TABLE 5. Contributions of GE channels

\begin{tabular}{lccccc}
\hline & \multicolumn{4}{c}{ Labor supply elasticity } \\
\cline { 2 - 3 } & \multicolumn{2}{c}{$G$ adjusts } & & \multicolumn{2}{c}{$T$ adjusts } \\
\cline { 2 - 3 } \cline { 5 - 6 } \cline { 5 - 6 } & HA model & RA model & & HA model & RA model \\
\hline Equilibrium response & 0.347 & 0.353 & & 0.898 & 0.827 \\
Direct response $(w, r, T$ fixed $)$ & 0.177 & 0.353 & & 0.177 & 0.353 \\
Direct response + wage channel & 0.189 & 0.353 & & 0.190 & 0.353 \\
& $(+0.013)$ & $(0.000)$ & & $(+0.013)$ & $(0.000)$ \\
Direct response + interest channel & 0.339 & 0.353 & & 0.398 & 0.353 \\
& $(+0.162)$ & $(0.000)$ & & $(+0.221)$ & $(0.000)$ \\
\hline
\end{tabular}

Notes: Reported values are the implied labor supply elasticity with respect to permanent tax changes. Numbers in the parentheses are the size of the elasticity relative to the counterpart in the second row (direct response).

LEMMA 1. The capital-to-labor ratio $\left(\frac{K}{E}\right)$ in the representative-agent model is independent of $\tau_{l}$ across steady states.

PROPOSITION 2. The equilibrium wage and interest rate in the representative-agent model are independent of $\tau_{l}$.

Because the equilibrium factor prices are a function of the capital-to-labor ratio that is independent of $\tau_{l}$, GE feedback in the representative-agent model is neutral $\left(\frac{\partial w}{\partial \tau_{l}}=\frac{\partial r}{\partial \tau_{l}}=0\right)$. According to (7), this implies that the equilibrium effects of labor taxes in the representative-agent model are solely due to the direct effects.

To summarize the decomposition exercises above, Table 5 reports the estimates of the labor supply elasticity using model-generated data from the heterogeneousagent model and the representative-agent model. Despite the similar elasticities in the first row based on the GE responses, the second row reveals that the direct responses that hold prices fixed are substantially weaker in the heterogeneousagent model. Table 5 also reports the difference in the contribution of each GE channel. ${ }^{16}$ First, note that adding each of the GE channels reinforces the direct employment response in the heterogeneous-agent model since the increments are all positive while GE feedback plays no role in the representative-agent model. Second, in the heterogeneous-agent model, adjustments of equilibrium interest rates are quantitatively much more significant in amplifying the elasticity (ranging from +0.16 to +0.22 ) than equilibrium wage adjustments (around +0.01 ).

\subsection{Inspecting the Transmission Mechanism}

This subsection investigates in detail the transmission mechanism quantified in the previous subsection. According to (7), the sign and magnitude of GE feedback driven by equilibrium price changes can be traced back to the two separate terms: (i) changes in market-clearing prices with respect to labor tax changes, $\frac{\partial w}{\partial \tau_{l}}$ and $\frac{\partial r}{\partial \tau_{l}}$, and (ii) changes in employment with respect to changes in wages and interest 
TABLE 6. Equilibrium effects of labor taxes in the heterogeneous-agent model

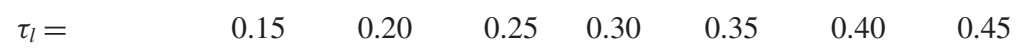

Equilibrium prices

$w(\% \mathrm{dev})$

$r$ (pp dev)

$\begin{array}{rrrrrrr}1.02 & 0.70 & 0.36 & 0.0 & -0.36 & -0.76 & -1.18 \\ -0.24 & -0.17 & -0.09 & 0.0 & 0.09 & 0.19 & 0.29\end{array}$

Aggregate allocations

$K(\% \mathrm{dev})$

$5.8 \quad 4.0$

$L$ (\% dev)

$2.9 \quad 2.0$

$\begin{array}{ll}2.1 & 0.0\end{array}$

$-2.4 \quad-5.0$

$-7.7$

$E(\% \mathrm{dev})$

$5.7 \quad 4.0$

1.1

$\begin{array}{lll}0.0 & -1.4 & -3.0\end{array}$

$-4.6$

Notes: This table is based on the assumption that $G$ adjusts with respect to a change in the labor tax. The unit of reported values in the second row is a percentage point deviation relative to the baseline model with a tax rate of 0.3 , whereas the unit of those in the other rows is a percent deviation.

rate rates, $\frac{\partial E}{\partial w}$ and $\frac{\partial E}{\partial r}$. Recall that in the representative-agent model, $\frac{\partial w}{\partial \tau_{l}}$ and $\frac{\partial r}{\partial \tau_{l}}$ are both zero (Proposition 2), implying that decomposition is trivial. Therefore, the analysis of this subsection focuses on the heterogeneous-agent model under the baseline assumption that $G$ adjusts with respect to labor tax changes.

The first two rows of Table 6 show how equilibrium prices change with respect to the labor tax rate $\tau_{l}{ }^{17} \mathrm{~A}$ key finding to note is that the equilibrium wage decreases with $\tau_{l}$, whereas the real interest rate increases with $\tau_{l}$. For example, an increase in $\tau_{l}$ from $30 \%$ to $45 \%$ leads the equilibrium wage to fall by $1.2 \%$, while it leads the interest rate to rise from $4.0 \%$ to $4.3 \%$.

Then the question is why a higher $\tau_{l}$ leads to lower wages and higher interest rates. As (1) and (2) show that changes in $w$ and $r$ crucially depend on the equilibrium capital-to-labor ratio $(K / L)$, the bottom three rows of Table 6 report how key aggregate variables, including $K$ and $L$, change with respect to $\tau_{l} \cdot{ }^{18}$ It shows that the response of aggregate efficiency unit of labor $L$ has the same sign but is substantially weaker than that of employment $E$ and aggregate capital stock $K$. This implies that a higher $\tau_{l}$ would decrease $K / L$, which in turn implies lower $w$ and higher $r$.

The finding that changes in $L$ are weaker than other aggregate variables in the heterogeneous-agent model can be traced to heterogeneous labor supply behavior across households. In the top panel of Figure 2, I plot how employment rates by (log) productivity are affected by the labor tax rate changes from $30 \%$ to either $15 \%$ (dashed line) or $45 \%$ (dash-dot line). Note that with respect to such sizeable labor tax changes, most employment changes are driven by workers with below median productivity. Since $L$ entails the composition of households with productivity $x_{i}$ who choose to work, its change can be much dampened compared to $E$ if the average productivity level of households who change their employment decision is lower than the average productivity level of workers. This is clearly the case in Figure 2.

The middle panel of Figure 2 plots the average asset holding choices by (log) productivity. Unlike employment decisions, households with high productivity 

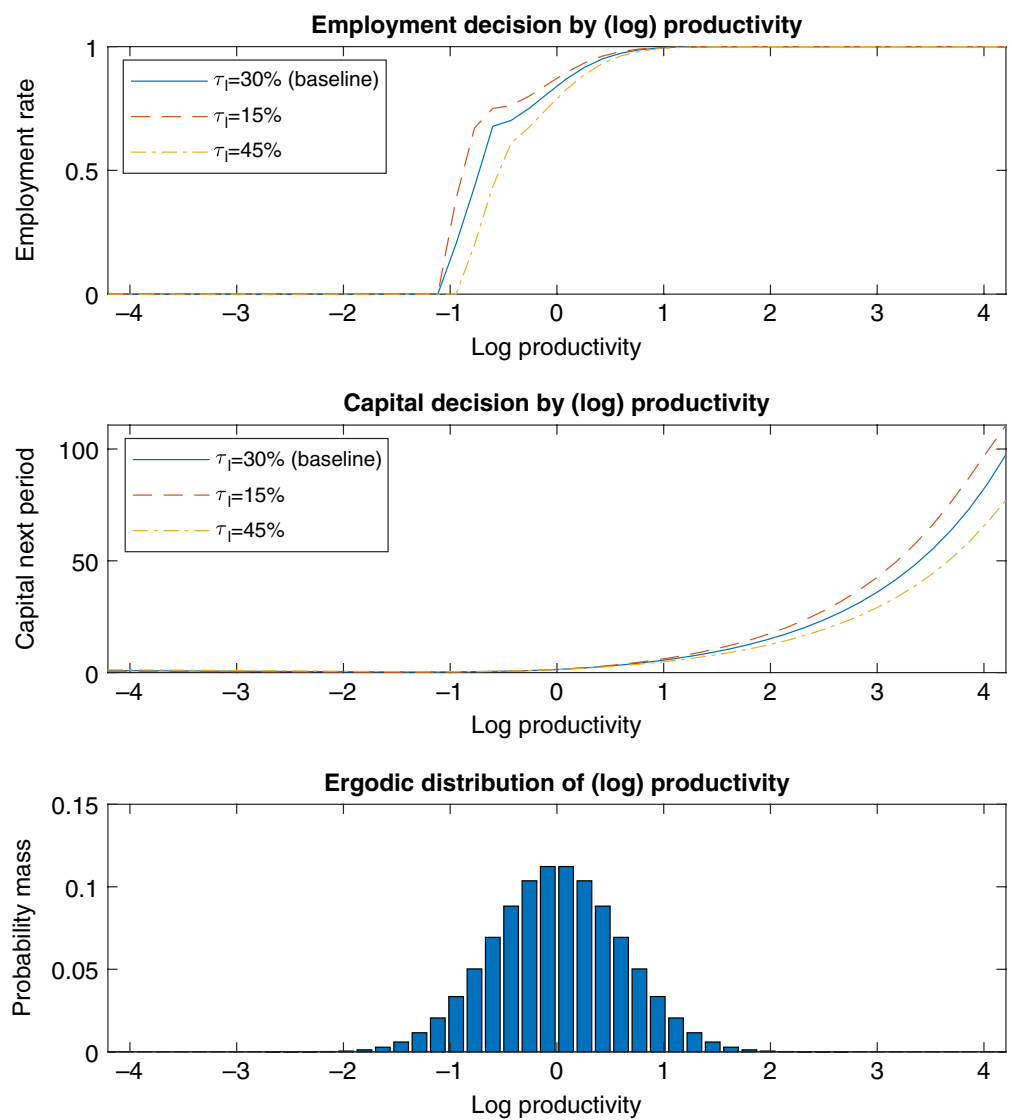

FIGURE 2. Employment and savings by productivity and the distribution of productivity.

change their savings decision quite substantially. Although highly productive households stay working in response to higher labor taxes $\tau_{l}$, their disposable labor income declines by a factor of the net-of-tax rate (i.e., $1-\tau_{l}$ ). These substantial saving responses of households with high productivity, who hold a large fraction of aggregate capital, make the aggregate capital stock to respond strongly to the labor tax change. This explains why $K$ responds more strongly than $L$ in Table 6, which is key for understanding why the ratio of capital to labor decreases with the labor tax rate.

I have so far investigated changes in market-clearing prices with respect to labor tax changes (i.e., $\frac{\partial w}{\partial \tau_{l}}$ and $\frac{\partial r}{\partial \tau_{l}}$ ). As emphasized earlier, the other important terms in identifying GE feedback channels are the employment responses to wages and interest rates (i.e., $\frac{\partial E}{\partial w}$ and $\frac{\partial E}{\partial r}$ ). Table 7 reports percentage point changes in employment obtained by changing market prices permanently from the baseline stationary equilibrium. The first two rows report the effects of wage changes on employment and show that higher wages lead to moderate increases in 
TABLE 7. Employment changes with respect to factor price changes

\begin{tabular}{lcccccc}
\hline & \multicolumn{5}{c}{ Employment changes } \\
\cline { 2 - 7 } & & \multicolumn{5}{c}{ By wealth quintile } \\
\cline { 2 - 7 } Unit: pp changes & In aggregate & First & Second & Third & Fourth & Fifth \\
\hline$\Delta w=+10 \%$ & 1.0 & 2.6 & 1.2 & 0.8 & 0.2 & 0.1 \\
$\Delta w=+20 \%$ & 1.9 & 6.6 & 0.8 & 1.1 & 0.7 & 0.1 \\
$\Delta r=-0.1 \mathrm{pp}$ & 1.0 & 0.0 & 0.4 & 1.3 & 1.3 & 1.8 \\
$\Delta r=-0.2 \mathrm{pp}$ & 1.9 & 0.0 & 0.8 & 2.3 & 2.9 & 3.5 \\
\hline
\end{tabular}

Notes: The reported values are obtained by changing each factor price permanently from the baseline stationary equilibrium. All reported values are relative to the values from the baseline model before factor price changes in percentage point changes.

aggregate employment. More interestingly, it also reveals that a lower interest rate increases aggregate employment quite substantially. For instance, a change in the real interest rate from $4 \%$ to $3.9 \%$ induces aggregate employment to rise by 1.0 percentage point, which is quantitatively very similar to the aggregate employment effect of a $10 \%$ wage increase. In other words, a seemingly small change in the interest rate such as 1 percentage point can be comparable to a quantitatively sizeable change in aggregate wage such as $10 \%$ when it comes to their impact on aggregate employment.

A closer look reveals that these similar aggregate employment responses are driven by very different households. Specifically, while wage changes affect the labor supply decisions of poor households more elastically, it is the rich households who adjust labor supply more elastically to a change in the interest rate. A lower real interest rate reduces asset demands (or capital supply), in particular of the rich households. The resulting negative income effects on labor supply raise employment, and, in particular, this effect is disproportionately stronger for the wealth-rich households.

\section{EMPIRICAL ANALYSIS USING CROSS-COUNTRY PANEL DATA}

The previous section has found that, in the heterogeneous-agent model, GE feedback through interest rate changes amplifies the negative employment impact of higher labor taxes, whereas it is neutral in the representative-agent model. In small SOEs, the equilibrium interest rate is less tightly linked to domestic circumstances. Therefore, the employment impact of labor taxes should be weaker in the SOEs according to the transmission mechanism of the heterogeneousagent model, while they should be similar according to the prediction of the representative-agent model.

To explore this theoretical implication, I construct a cross-country panel data set combined from different data sources. The key variables are extensive margin variations and labor tax rates. Data on the extensive margin of labor supply 
are obtained from the Conference Board database "International Comparisons of Annual Labor Force Statistics," which covers from 1970 to 2013. In the following analysis, I present the results using both employment-population ratios and labor force participation rates. For the other key variable - the labor tax rate, I use the updated tax data set of McDaniel (2007), which was extended up to 2013 for most countries in her sample. The key question in this section is concerned with SOEs. I divide the whole sample into two categories: SOEs and non-SOEs. Specifically, a country in a certain year is defined as an SOE if the country is both small and open in that year. ${ }^{19}$

I begin by plotting the relationship between labor tax rates and labor supply at the extensive margin in Figure 3. In the left panel, the extensive margin labor supply is measured by (log) employment-population ratios and, in the right panel, it is measured by (log) labor force participation rates. Each panel shows their relationship among SOEs (right) and among non-SOEs (left), separately. First, note that all four relationships in Figure 3 suggest that a higher labor tax rate is associated with a lower labor supply at the extensive margin. This is consistent with the literature that finds that labor taxes are an important determinant of crosscountry differences in total hours worked [Prescott (2004), Ohanian et al. (2008), and Rogerson (2008) among others].

A more striking and new finding is that this negative relationship is much weaker among SOEs than non-SOEs in both panels. To investigate this finding more carefully, consider panel regressions that extend (6). Specifically, I estimate the extensive margin elasticity gap in SOEs relative to non-SOEs using the following equation:

$$
\log E_{i t}=\beta_{0}+\beta_{1} \log \left(1-\tau_{i t}\right)+\beta_{2} I\left(\text { soe }_{i t}\right) \log \left(1-\tau_{i t}\right)+\text { controls }+\varepsilon_{i t},
$$

where $I\left(\operatorname{soe}_{i t}\right)$ is an indicator function which is 1 for SOEs and is 0 otherwise. Then, $\beta_{2}$ would capture an increment of the extensive margin elasticity among SOEs relative to non-SOEs. If $\beta_{2}$ is not different from zero, then one cannot reject the null hypothesis that the extensive margin elasticity is the same between SOEs and the others. Note that the main purpose of this regression analysis is not to identify the unbiased estimates of the extensive margin elasticity but rather to test if the association between labor tax rates and the extensive margin labor supply found in Figure 3 is robust. Thus, I include control variables such as country fixed effects, year fixed effects, and log income per capita $\left(y_{i t}\right)$. Country fixed effects can capture various unobservable heterogeneity at the country level. Given the potential existence of unobserved heterogeneity across countries, the inclusion of country fixed effects can be preferred in this type of cross-country regressions. Next, it is useful to include year fixed effects and log income per capita in order to control for business cycle fluctuations. Note that log income per capita may also capture overall wage growth, which itself may affect the employment rate. Table 8 reports the estimation results using both measures of the extensive margin labor supply. Column (1) does not include any control variables. Columns (2)-(8) include a different combination of control variables explained above. 

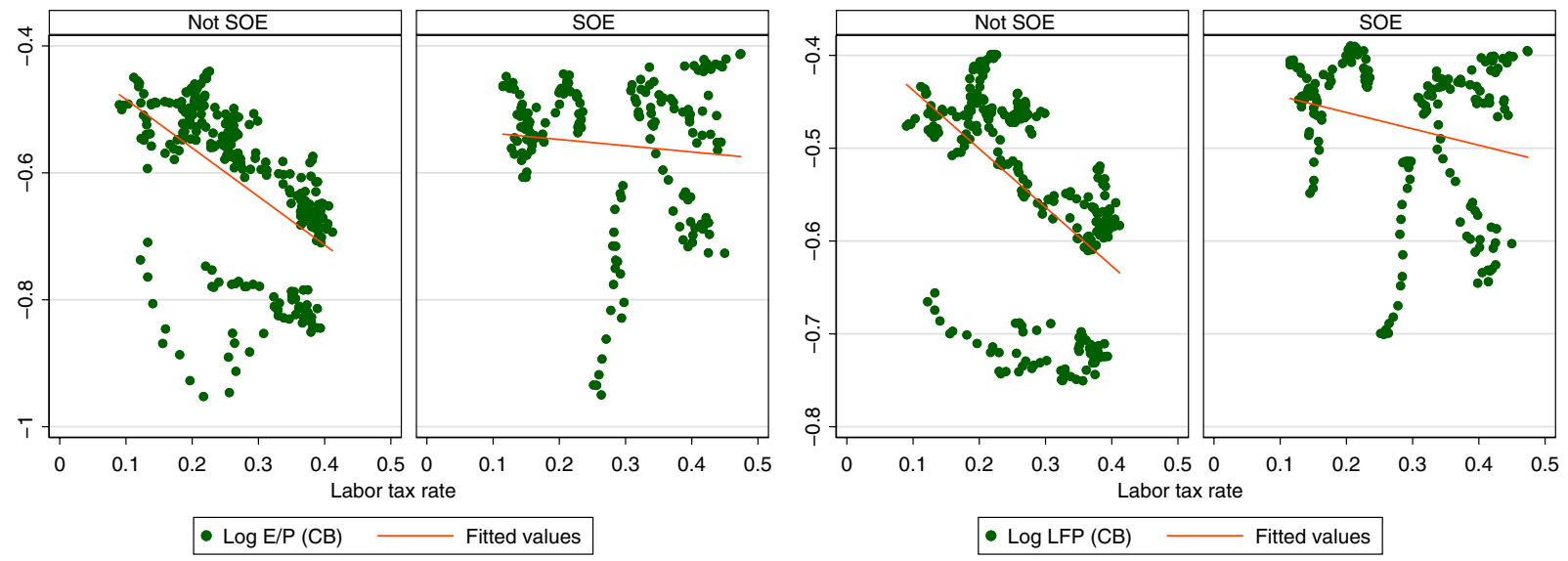

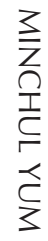

Notes: The left panel plots the log employment-population ratio against the labor tax rate. The right panel plots the log labor force participation rate against the labor tax rate. An SOE is defined based on the long-run GDP and the degree of financial openness according to the Chinn-Ito Index.

FIGURE 3. Labor taxes and extensive margin labor supply. 
TABLE 8. Extensive margin elasticities in SOEs vs. non-SOEs

\begin{tabular}{|c|c|c|c|c|c|c|c|c|}
\hline & (1) & (2) & (3) & (4) & (5) & (6) & (7) & (8) \\
\hline \multicolumn{9}{|c|}{ Dependent variable: $\log ($ employment-pop ratio) } \\
\hline \multirow[t]{2}{*}{$\beta_{1}$} & 0.433 & 0.478 & 0.427 & 0.448 & 0.466 & 0.648 & 0.589 & 0.514 \\
\hline & $(0.162)$ & $(0.157)$ & $(0.192)$ & $(0.158)$ & $(0.142)$ & $(0.193)$ & $(0.242)$ & $(0.233)$ \\
\hline \multirow[t]{2}{*}{$\beta_{2}$} & -0.244 & -0.225 & -0.243 & -0.191 & -0.289 & -0.270 & -0.292 & -0.230 \\
\hline & $(0.137)$ & (0.149) & $(0.146)$ & $(0.149)$ & $(0.108)$ & $(0.097)$ & $(0.108)$ & $(0.111)$ \\
\hline Adjusted $R^{2}$ & 0.219 & 0.291 & 0.165 & 0.366 & 0.852 & 0.876 & 0.871 & 0.886 \\
\hline \multicolumn{9}{|c|}{ Dependent variable: $\log$ (participation rate) } \\
\hline \multirow[t]{2}{*}{$\beta_{1}$} & 0.411 & 0.456 & 0.437 & 0.451 & 0.172 & 0.357 & 0.412 & 0.385 \\
\hline & $(0.132)$ & $(0.132)$ & $(0.158)$ & $(0.136)$ & $(0.140)$ & $(0.162)$ & $(0.208)$ & $(0.205)$ \\
\hline \multirow[t]{2}{*}{$\beta_{2}$} & -0.243 & -0.225 & -0.243 & -0.252 & -0.231 & -0.211 & -0.247 & -0.225 \\
\hline & $(0.116)$ & $(0.124)$ & $(0.126)$ & $(0.126)$ & $(0.105)$ & $(0.077)$ & $(0.095)$ & $(0.091)$ \\
\hline Adjusted $R^{2}$ & 0.302 & 0.408 & 0.266 & 0.394 & 0.868 & 0.907 & 0.898 & 0.901 \\
\hline $\log \left(y_{i t}\right)$ & No & Yes & No & Yes & No & Yes & No & Yes \\
\hline Year FE & No & No & Yes & Yes & No & No & Yes & Yes \\
\hline Country FE & No & No & No & No & Yes & Yes & Yes & Yes \\
\hline Observations & \multicolumn{8}{|c|}{468} \\
\hline
\end{tabular}

Note: Numbers in parentheses are standard errors of the above estimates, clustered at the country level.

The key results are summarized as follows. First, note that the estimate of $\beta_{1}$ is positive in all specifications (1)-(8) of both tables and is statistically significant at the $95 \%$ confidence level in most specifications with the robust standard errors, clustered at the country level. This estimate measures the percentage change in the extensive margin labor supply with respect to a percentage change in the net-of-tax rate (i.e., the extensive margin labor supply elasticity) in non-SOEs. Interestingly, the estimate of $\beta_{1}$ is quite sizeable, ranging from 0.4 to 0.6 when the employment-population ratio is used. ${ }^{20}$

More importantly, the estimate of $\beta_{2}$ that captures the increment of the elasticity for SOEs is negative in all specifications. In both tables, the point estimates are robustly around $-0.25 .^{21}$ This is economically meaningful, given the magnitude of the estimate of $\beta_{1}$. The above panel regressions with various controls suggest that the key finding of Figure 3 that the labor tax rates are weakly associated with the extensive margin labor supply in SOEs is a robust feature of the data. This supports the heterogeneous-agent model over the representative-agent model, the former of which highlights equilibrium interest rates as an important amplification channel through which labor taxes reduce the extensive margin labor supply.

\section{CONCLUDING REMARKS}

In this paper, I have explored the role of GE channels in the employment effects of labor tax changes. I have found that GE feedback, in particular of interest rate adjustments, reinforces the negative employment impact of higher 
labor taxes in the heterogeneous-agent model, whereas GE plays no role in the representative-agent model. A key underlying reason for this is shown to be heterogeneous labor supply responses and savings decisions across households in the heterogeneous-agent model. Using the cross-country panel data, I have found that, in SOEs, where the equilibrium interest rate is less tightly linked to the domestic circumstances, the employment effects of labor taxes are much weaker.

The findings in this paper have some important implications. First, the role of equilibrium interest rates found in this paper implies that the exogenously fixed interest rate in model economies used to investigate the effects of labor taxes may not be innocuous. Relatedly, this paper highlights the importance of incorporating capital markets even when the key object of interest is the effects of labor taxes. Lastly, this paper provides a counterexample to the conventional view that GE feedback is a dampening force.

A novel empirical finding in this paper is the difference in the degree of negative relationship between labor taxes and aggregate employment in SOEs. Although the key mechanism considered in this paper can be an important underlying source of this relationship, there could also be alternative explanations for this weaker negative relationship between labor taxes and the extensive margin labor supply in SOEs. This interesting exploration is left for future work.

\section{SUPPLEMENTARY MATERIAL}

To view supplementary material for this article, please visit https://doi.org/ $10.1017 / \mathrm{S} 1365100519000087$.

\section{NOTES}

1. For example, it has been at the center of a wide range of macroeconomic analysis since the seminal work of Prescott (2004), which has demonstrated that differences in labor tax rates can largely account for the observed cross-country differences in aggregate hours worked. See also Ohanian et al. (2008) and Rogerson (2008) who further find the important role of tax changes in accounting for aggregate hours across countries and over time.

2. For instance, the literature has explored the roles of various features that introduce richer heterogeneity at the micro level, including life cycles, human capital accumulation, gender differences, marriage, and labor market frictions. See, for example, Chang and Kim (2006), Krusell et al. (2008, 2010), Ljungqvist and Sargent (2008), Rogerson and Wallenius (2009), Alonso-Ortiz and Rogerson (2010), Guner et al. (2012), Chakraborty et al. (2015), Erosa et al. (2016), Karabarbounis (2016), and Bick and Fuchs-Schündeln (2017) among others.

3. In order to fairly compare the effects of taxes between the heterogeneous-agent model and the representative-agent model, the exercises control for either transfers or government purchases at the baseline level in both models.

4. This elasticity is based on steady-state comparison with respect to permanent tax changes while transfers are held fixed. When transfers adjust, the role of interest rates is still large (increasing it from 0.18 to 0.40 ). Note that these steady-state elasticities are generally smaller than the intertemporal elasticity with respect to temporary tax changes (Chetty et al., 2012).

5. Alonso-Ortiz and Rogerson (2010) explore the implication of this mechanism for social welfare and the cross-country differences in average labor productivity. Yum (2018) focuses on the role of transfers for this mechanism and its implication for the aggregate labor supply elasticity. 
6. These analyses are along the same line as the literature that studies whether heterogeneity matters for aggregate fluctuations [e.g., Krusell and Smith (1998), Thomas (2002), Chang and Kim (2007), Khan and Thomas (2008), and Krueger et al. (2016)].

7. Note that $G$ is not the focus of the paper and is assumed to be not valued by households (or equivalently, it is valued by households in an additively separable manner).

8. Adopting such a utility function for the representative household, the model is essentially a steady-state version of Hansen (1985) augmented with the government.

9. The heterogeneous-agent model is solved and simulated numerically. The value functions and the decision rules are stored on 100 grid points for $a$, which are spaced unevenly, and $x$ with $N_{x}=50$. The value functions are interpolated using cubic splines. To approximate the distribution $\mu$, I use a much finer grid (3000 points) over assets. The representative-agent model is solved analytically.

10. This rate is close to the average tax rate and is lower than the US marginal tax rate of 0.4 computed in Prescott (2004). The main results are not sensitive to alternative baseline tax rates around 0.3 .

11. Supplementary Appendix provides the detailed description on how transfers related to income security are measured in the SIPP data.

12. The range of the labor tax rates I consider is \pm 15 percentage point around the baseline rate of $30 \%$. The range is broadly in line with cross-country variations of labor taxes in the data set constructed by McDaniel (2007). The employment effects are expressed as a percentage change relative to the benchmark case with $\tau_{l}=0.3$.

13. See Ljungqvist and Sargent (2008) and Alonso-Ortiz and Rogerson (2010).

14. The decomposition is for the baseline case where $G$ adjusts with respect to $\tau_{l}$. As noted above, the decomposition would require feedback from transfers in the case when $T$ adjusts instead.

15. Hence, the mirror image of the solid line corresponds to the first row of Table 4.

16. The numbers in the parentheses show the size of the elasticity relative to the counterpart in the second row (direct responses).

17. Wage changes are shown in percentage change relative to the baseline case with $\tau_{l}=0.3$ while interest rate changes are shown in percentage point change.

18. They are expressed in percentage change relative to the case with $\tau_{l}=0.3$.

19. See Supplementary Appendix for details on categorization and data on openness (Chinn and Ito (2006)).

20. For example, Chetty et al. (2012) obtain 0.25 following Prescott (2004). A key difference herein is that the estimate of $\beta_{1}$ in Table 8 captures the employment effects of net-of-taxes excluding the SOEs.

21. In particular, it is statistically significant in specifications (5)-(7) using the employmentpopulation ratio and in specifications (6)-(8) using the labor force participation rate at the $95 \%$ confidence level.

\section{REFERENCES}

Aiyagari, S. R. (1994) Uninsured idiosyncratic risk and aggregate saving. The Quarterly Journal of Economics 109, 659-684.

Alonso-Ortiz, J. and R. Rogerson (2010) Taxes, transfers and employment in an incomplete markets model. Journal of Monetary Economics 57, 949-958.

Bick, A. and N. Fuchs-Schündeln (2017) Taxation and labour supply of married couples across countries: A macroeconomic analysis. The Review of Economic Studies 85, 1543-1576.

Chakraborty, I., H. A. Holter and S. Stepanchuk (2015) Marriage stability, taxation and aggregate labor supply in the US vs. Europe. Journal of Monetary Economics 72, 1-20.

Chang, Y. and S.-B. Kim (2006) From individual to aggregate labor supply: A quantitative analysis based on a heterogeneous agent macroeconomy. International Economic Review 47, $1-27$.

Chang, Y. and S.-B. Kim (2007) Heterogeneity and aggregation: Implications for labor-market fluctuations. American Economic Review 97, 1939-1956. 
Chetty, R., A. Guren, D. Manoli and A. Weber (2012) Does indivisible labor explain the difference between micro and macro elasticities? A meta-analysis of extensive margin elasticities. In: NBER Macroeconomics Annual 2012, Volume 27, University of Chicago Press.

Chinn, M. D. and H. Ito (2006) What matters for financial development? Capital controls, institutions, and interactions. Journal of Development Economics 81, 163-192.

Domeij, D. and J. Heathcote (2004) On the distributional effects of reducing capital taxes. International Economic Review 45, 523-554.

Erosa, A., L. Fuster and G. Kambourov (2016) Towards a micro-founded theory of aggregate labour supply. The Review of Economic Studies 83, 1001-1039.

Guner, N., R. Kaygusuz and G. Ventura (2012) Taxation and household labour supply. Review of Economic Studies 79, 1113-1149.

Hansen, G. D. (1985) Indivisible labor and the business cycle. Journal of Monetary Economics 16, 309-327.

Huggett, M. (1993) The risk-free rate in heterogeneous-agent incomplete-insurance economies. Journal of Economic Dynamics and Control 17, 953-969.

Imrohoroğlu, A. (1989) Cost of business cycles with indivisibilities and liquidity constraints. Journal of Political Economy 97, 1364-1383.

Karabarbounis, M. (2016) A road map for efficiently taxing heterogeneous agents. American Economic Journal: Macroeconomics 8, 182-214.

Khan, A. and J. K. Thomas (2008) Idiosyncratic shocks and the role of nonconvexities in plant and aggregate investment dynamics. Econometrica 76, 395-436.

Krueger, D., K. Mitman and F. Perri (2016) Macroeconomics and household heterogeneity. Handbook of Macroeconomics 2, 843-921.

Krusell, P., T. Mukoyama, R. Rogerson and A. Şahin (2008) Aggregate implications of indivisible labor, incomplete markets, and labor market frictions. Journal of Monetary Economics 55, 961-979.

Krusell, P., T. Mukoyama, R. Rogerson and A. Şahin (2010) Aggregate labor market outcomes: The roles of choice and chance. Quantitative Economics 1, 97-127.

Krusell, P. and J.-V. Rios-Rull (1999) On the size of US Government: Political economy in the neoclassical growth model. American Economic Review 89, 1156-1181.

Krusell, P. and A. A. Smith Jr. (1998) Income and wealth heterogeneity in the macroeconomy. Journal of Political Economy 106, 867-896.

Ljungqvist, L. and T. J. Sargent (2008) Taxes, benefits, and careers: Complete versus incomplete markets. Journal of Monetary Economics 55, 98-125.

McDaniel, C. (2007) Average tax rates on consumption, investment, labor and capital in the OECD 1950-2003. Unpublished Manuscript.

Ohanian, L., A. Raffo and R. Rogerson (2008) Long-term changes in labor supply and taxes: Evidence from OECD countries, 1956-2004. Journal of Monetary Economics 55, 1353-1362.

Prescott, E. C. (2004) Why do Americans work so much more than Europeans? Federal Reserve Bank of Minneapolis Quarterly Review 28, 2-13.

Rogerson, R. (1988) Indivisible labor, lotteries and equilibrium. Journal of Monetary Economics 21, 3-16.

Rogerson, R. (2008) Structural transformation and the deterioration of European labor market outcomes. Journal of Political Economy 116, 235-259.

Rogerson, R. and J. Wallenius (2009) Micro and macro elasticities in a life cycle model with taxes. Journal of Economic Theory 144, 2277-2292.

Rouwenhorst, K. G. (1995) Asset pricing implications of equilibrium business cycle models. In: T. F. Cooley (ed.) Frontiers of Business Cycle Research, pp. 294-330. Princeton, NJ: Princeton University Press.

Thomas, J. K. (2002) Is lumpy investment relevant for the business cycle? Journal of Political Economy 110, 508-534.

Trabandt, M. and H. Uhlig (2011) The Laffer curve revisited. Journal of Monetary Economics 58, 305-327.

Yum, M. (2018) On the distribution of wealth and employment. Review of Economic Dynamics 30, $86-105$. 